\title{
A Case of Successful Conservative Management of Multiple Facial Bone Fractures in an Infant
}

\author{
Kazutaka Soejima ${ }^{1 *}$, Katsumi Shimoda ${ }^{1}$, Yumi Tanabe ${ }^{2}$, Takashi Yamaki², Taro Kono ${ }^{2}$, Ryohei Higuchi ${ }^{3}$ Hiroyuki Sakurai $^{2}$ and Hiroak \\ Nakazawa $^{1}$ \\ ${ }^{1}$ Department of Plastic and Reconstructive Surgery, School of Medicine, Nihon University, 30-1 Kamicho, Oyaguchi, Itabashi-ku, Tokyo 173-8610, Japan \\ ${ }^{2}$ Department of Plastic and Reconstructive Surgery, Tokyo Women's Medical University, 8-1 Kawadacho, Shinjuku-ku, Tokyo 162-8666, Japan \\ ${ }^{3}$ Department of Plastic and Reconstructive Surgery, Tokyo Metropolitan Tama Medical Center, 2-8-9 Musashidai, Fuchu-shi, Tokyo 18308524, Japa
}

\begin{abstract}
Displaced facial fractures in infants are rare, with only limited published data, and management of such fractures remains controversial. Various authors have advocated managing severely displaced fractures by open reduction and rigid fixation. We describe our experience in successfully managing a case of multiple fractures of facial bones in an infant by conservative observation.

A 17-month-old boy sustained multiple facial fractures in a car accident. A CT scan revealed a severely displaced left zygomatic fracture and an undisplaced mandibular angle fracture. There was no orbital floor defect with entrapment of orbital soft tissue. The patient was managed by conservative observation and the outcome was satisfactory. There was complete remodeling of the severely displaced zygomatic fracture. To our knowledge, there are few or no reports on the management of severe facial fractures in infants by conservative observation. The present case suggests the wisdom of deciding the treatment method for facial fractures in infants only after careful observation and consideration.
\end{abstract}

Keyword: Pediatric maxillofacial injuries; Facial fractures; Fracture of facial bone; Facial skeleton

\section{Introduction}

Fractures of the facial skeleton are rare in children compared to in adults [1-8]. Pediatric maxillofacial injuries were reported to comprise less than $15 \%$ of all facial fractures [1-3]. In Imahara's survey of the National Trauma Data Bank (2001 to 2005) in the United States, 277,008 pediatric trauma patients (age 0 to 18 years) included 12,739 (4.6\%) who had sustained facial fractures [8]. The incidence of facial fractures increased with age, and the lowest incidence was in infants (age 0 to 1 year, $n=722 / 12,739,5.7 \%$ ) [8]. In addition, fractures in children tend to be minimally displaced, especially in infants, because of the elasticity of the bones, flexibility of the suture lines and lack of sinus pneumatization $[2,3,8]$. Hence, displaced facial fractures in infants are rare, and few have been reported in the literature. Here, we describe a case of multiple fractures of facial bones in an infant, which we successfully managed by conservative observation.

\section{Case report}

A 17-month-old male child without medical history was involved in a motor vehicle collision when his father drove his car into the back of a crane truck. The baby was sitting in the rear of the car, without any child seat.

He was taken to a municipal hospital, and a computed tomography (CT) scan showed fractures of the left zygoma and mandible (Figure 1). He was referred to our hospital the next day. He had severe swelling on the injured side of his face (Figure 2), but he was conscious and his vital signs were normal. Physical examinations, such as tests of eye movement, mouth opening, occlusion and sensation in the infraorbital nerve area, could not be conducted because of difficulty in cooperation. A new CT scan was performed under sedation because the data from the previous hospital were insufficient for planning treatment.

Our CT scan revealed a tripod fracture of the left zygoma, classified in Knight \& North's classification as group V [9], and a fracture of the left mandibular angle. Although the zygomatic bone was severely displaced, there was no orbital blow-out fracture and the mandibular angle was undisplaced (Figure 3). Thus, we waited for 1 week to decide the treatment method.

A fresh CT scan taken after 1 week revealed that the zygomatic deviation had improved, with a shift of the zygoma in the medial direction (Figure 4). Although the malar region could not be evaluated for possible diplopia and hypesthesia, the swelling subsided and the limitation of opening the mouth was not remarkable (Figure 5). Therefore, we decided to manage this case by conservative observation with radiological follow-up. No diet limitation was necessary because he was suckling.

Two months later, a CT scan showed further improvement of the zygomatic deviation and completion of bone union at the mandibular fracture (Figure 6). One year after the trauma, a CT scan revealed that the zygomatic deviation was completely corrected (Figure 7). His parents did not complain of anything, including his facial contour, mouth opening, eye movement, occlusion and ability to eat baby food (Figure 8).

\section{Discussion}

The management of facial fractures in children remains controversial [10-18]. The published literature provides little in regard to standard treatment protocols for pediatric facial fractures, but

*Corresponding author: Kazutaka Soejima, Department of Plastic and Reconstructive Surgery, School of Medicine, Nihon University, 30-1 Kamicho, Oyaguchi, Itabashi-ku, Tokyo 173-8610, Japan, Tel: +81-3-3972-8111; Fax: +81-33972-8860; E-mail: soejima.kazutaka@nihon-u.ac.jp

Received January 19, 2012; Accepted February 01, 2012; Published February 06, 2012

Citation: Soejima K, Shimoda K, Tanabe Y, Yamaki T, Kono T, et al. (2012) A Case of Successful Conservative Management of Multiple Facial Bone Fractures in an Infant. J Trauma Treatment 1:111. doi:10.4172/2167-1222.1000111

Copyright: (c) 2012 Soejima K, et al. This is an open-access article distributed under the terms of the Creative Commons Attribution License, which permits unrestricted use, distribution, and reproduction in any medium, provided the original author and source are credited. 
Citation: Soejima K, Shimoda K, Tanabe Y, Yamaki T, Kono T, et al. (2012) A Case of Successful Conservative Management of Multiple Facial Bone Fractures in an Infant. J Trauma Treatment 1:111. doi:10.4172/2167-1222.1000111

there has been some advocacy of open reduction and rigid fixation for management of severely displaced fractures $[10,11,15]$. However, some animal studies demonstrated adverse effects of rigid fixation on cranial facial growth $[19,20]$. Undermining of the periosteum may contribute to disturbance of skeletal growth. Even if resorbable plates and screws are used, there is the risk that screws will traumatize tooth buds or erupting teeth. On the other hand, it is generally accepted that stable, undisplaced and asymptomatic fractures are indications for conservative, non-surgical treatment $[3,13,18]$.

For the present case, we were irresolute at the beginning, because the zygomatic bone was severely displaced. However, a CT scan confirmed the absence of any orbital floor defect with entrapment of orbital contents and the fact that the mandibular fracture was undisplaced. This knowledge convinced us to "watch and wait," with the expectation that functional deficits such as diplopia and malocclusion could be avoided. The mandibular fracture in this child was at the mandibular angle, which is the second most common site of fracture in children younger than 5 years of age $[8,21]$. Complications such as malocclusion and malunion following conservative therapy in children are very rare [21]. Therefore, our greatest concern was the outcome of the severely displaced zygomatic fracture.
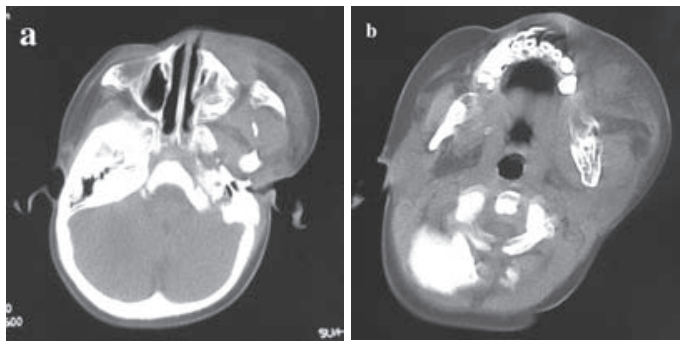

Figure 1: A CT scan taken at the previous hospital. a: horizontal view of the zygoma, b: horizontal view of the mandible.

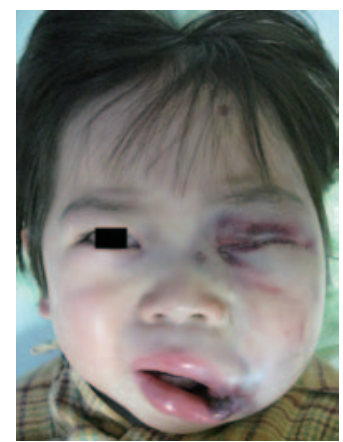

Figure 2: The patient had severe swelling of his injured face.
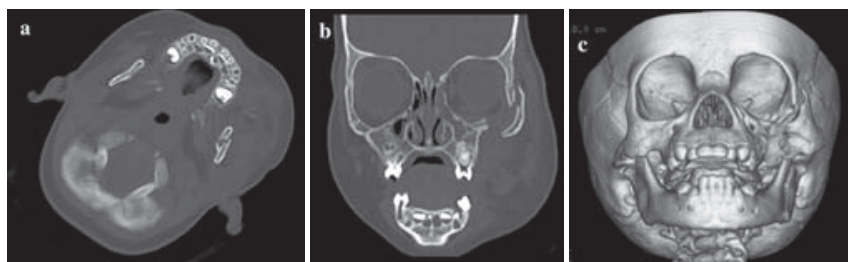

Figure 3: Initial CT scan taken at our hospital. a: horizontal view of the mandible, b: coronal view of the zygoma and the orbital complex, c: 3D CT of the facial bones.
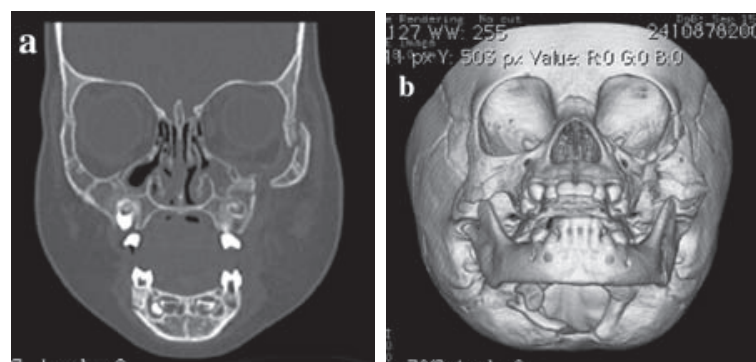

Figure 4: A CT scan taken 7 days after the trauma. a: coronal view of the zygoma and the orbital complex, b: 3D CT of the facial bones.

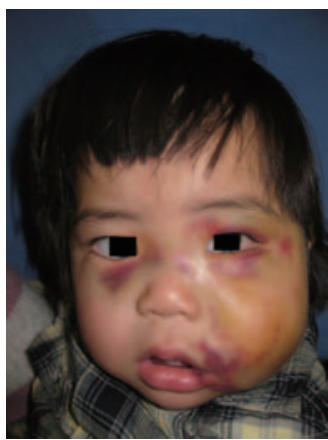

Figure 5: The facial swelling had subsided.
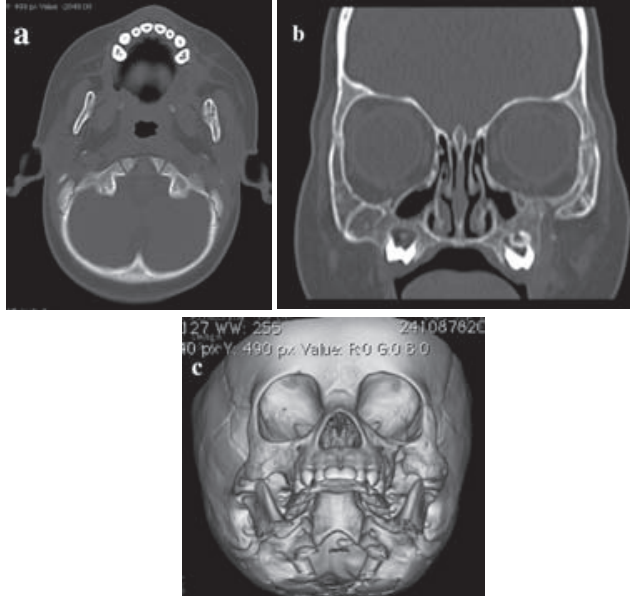

Figure 6: A CT scan taken 2 months after the trauma. a: coronal view of the zygoma and the orbital complex, b: 3D CT of the facial bones.

The potential for remodeling of the mandibular condyle [22] and nasal fractures [23] of the growing facial skeleton are well known, but few data have been published regarding remodeling of other facial regions, including the zygomatic bone. Thus, the complete remodeling of the severely displaced zygomatic fracture that we have documented here for our case represents important information for clinicians dealing with pediatric facial fractures. To our knowledge, there have been few reports of management of severe facial fractures in infants by conservative observation. We hope to perform long-term follow-up of our patient in the future.

In summary, a 17-month-old patient sustained multiple facial fractures in a car accident. A CT scan revealed a severely displaced 
Citation: Soejima K, Shimoda K, Tanabe Y, Yamaki T, Kono T, et al. (2012) A Case of Successful Conservative Management of Multiple Facial Bone Fractures in an Infant. J Trauma Treatment 1:111. doi:10.4172/2167-1222.1000111

Page 3 of 3
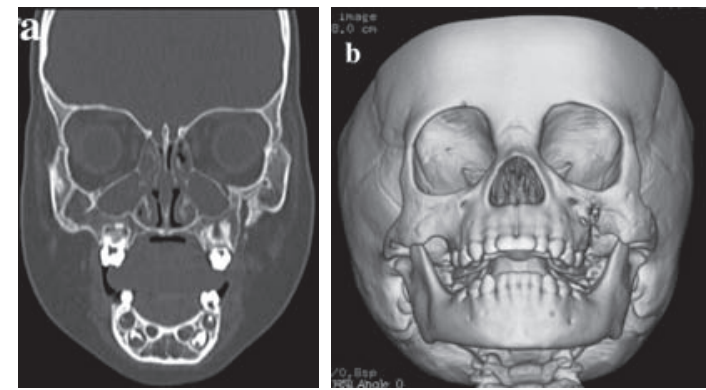

Figure 7: A CT scan taken 1 year after the trauma. a: coronal view of the zygoma and the orbital complex, b: 3D CT of the facial bones.

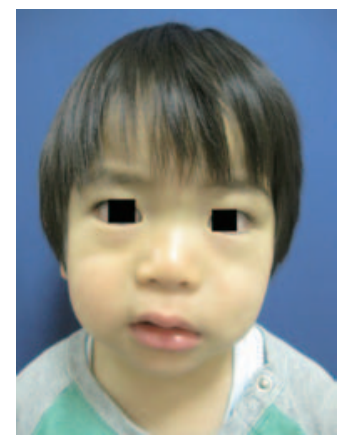

Figure 8: A satisfactory outcome was obtained.

left zygomatic fracture and an undisplaced mandibular angle fracture. The absence of any orbital floor defect with entrapment of orbital soft tissue was confirmed in the coronal view of the CT scan. The patient was managed conservatively, and the outcome was highly satisfactory. Our experience with the present case supports the concept that the treatment approach for facial fractures in infants should be decided after careful consideration and observation.

\section{References}

1. Rowe NL (1968) Fractures of the facial skeleton in children. J Oral Surg 26: 505-515.

2. Stylogianni L, Arsenopoulos A, Patrikiou A (1991) Fractures of the facial skeleton in children. Br J Oral Maxillofac Surg 29: 9-11.

3. Zimmermann CE, Troulis MJ, Kaban LB (2006) Pediatric facial fractures: recent advances in prevention, diagnosis and management. Int $\mathrm{J}$ Oral Maxillofac Surg 35: 2-13.

4. Alcalá-Galiano A, Arribas-García IJ, Martín-Pérez MA, Romance A, Montalvo-Moreno JJ, et al. (2008) Pediatric facial fractures: children are not just small adults. Radiographics 28: 441-461.

5. Haug RH, Foss J (2000) Maxillofacial injuries in the pediatric patient. Oral Surg Oral Med Oral Pathol Oral Radiol Endod 90: 126-134.

6. Posnick JC, Wells M, Pron GE (1993) Pediatric facial fractures: evolving patterns of treatment. J Oral Maxillofac Surg 51: 836-844.

7. Zerfowski M, Bremerich A (1998) Facial trauma in children and adolescents. Clin Oral Investig 2: 120-124.

8. Imahara SD, Hopper RA, Wang J, Rivara FP, Klein MB (2008) Patterns and outcomes of pediatric facial fractures in the United States: a survey of the National Trauma Data Bank. J Am Coll Surg 207: 710-716.

9. Knight JS, North JF (1961) The classification of malar fractures: an analysis of displacement as a guide to treatment. Br J Plast Surg 13: 325-339.
10. Koltai PJ, Rabkin D, Hoehn J (1995) Rigid fixation of facial fractures in children. J Craniomaxillofac Trauma 1: 32-42.

11. Eppley BL (2005) Use of resorbable plates and screws in pediatric facial fractures. J Oral Maxillofac Surg 63: 385-391.

12. Back CP, McLean NR, Anderson PJ, David DJ (2007) The conservative management of facial fractures: indications and outcomes. J Plast Reconstr Aesthet Surg 60: 146-151.

13. Hatef DA, Cole PD, Hollier LH Jr (2009) Contemporary management of pediatric facial trauma. Curr Opin Otolaryngol Head Neck Surg 17: 308-314.

14. Chrcanovic BR, Abreu MH, Freire-Maia B, Souza LN (2010) Facial fractures in children and adolescents: a retrospective study of 3 years in a hospital in Belo Horizonte, Brazil. Dent Traumatol 26: 262-270.

15. Iatrou I, Theologie-Lygidakis N, Tzerbos F (2010) Surgical protocols and outcome for the treatment of maxillofacial fractures in children: 9 years experience. J Craniomaxillofac Surg 38: 511-516.

16. Muñante-Cárdenas JL, Olate $\mathrm{S}$, Asprino L, de Albergaria Barbosa JR, de Moraes M, et al. (2011) Pattern and treatment of facial trauma in pediatric and adolescent patients. J Craniofac Surg 22: 1251-1255.

17. Rottgers SA, Decesare G, Chao M, Smith DM, Cray JJ, et al. (2011) Outcomes in pediatric facial fractures: early follow-up in 177 children and classification scheme. J Craniofac Surg 22: 1260-1265.

18. Bartlett SP, DeLozier JB 3rd (1992) Controversies in the management of pediatric facial fractures. Clin Plast Surg 19: 245-258.

19. Polley JW, Figueroa A, Hung KF, Cohen M, Lakars T (1995) Effect of rigid microfixation on the craniomaxillofacial skeleton. J Craniofac Surg 6: 132138.

20. Eppley BL, Platis JM, Sadove AM (1993) Experimental effects of bone plating in infancy on craniomaxillofacial skeletal growth. Cleft Palate Craniofac J 30 164-169.

21. Oji C (1998) Fractures of the facial skeleton in children: a survey of patients under the age of 11 years. J Craniomaxillofac Surg 26: 322-325.

22. Leake D, Doykos J 3rd, Habal MB, Murray JE (1971) Long-term follow-up of fractures of the mandibular condyle in children. Plast Reconstr Surg 47: 127-131.

23. Grymer LF, Gutierrez C, Stoksted P (1985) The importance of nasal fractures during different growth periods of the nose. J Laryngol Otol 99: 741-744. 